\title{
Surveillance of Animal Rabies in Burkina Faso: A Retrospective Laboratory Data from 2008 to 2012
}

\author{
Germaine Minoungou ${ }^{1}$, L. Dieudonné Dahourou ${ }^{2 *}$, Madi Savadogo ${ }^{3}$, Dieudonné Tialla ${ }^{3}$, Alima \\ Hadjia Banyala Combari ${ }^{4}$, Estelle Kanyala ${ }^{5}$, Lassina Ouattara ${ }^{1}$, Sonia Anne Kabore ${ }^{1}$, Victorine \\ Ouedraogo $^{1}$, Yaya Tabouret ${ }^{1}$ and Issa Kere ${ }^{1}$
}

${ }^{1}$ National Livestock Laboratory, PO box 7026, Ouagadougou 03, Burkina Faso: ${ }^{2}$ University of Dedougou, PO box 176 Dedougou, Burkina Faso: ${ }^{3}$ Research Institute for Health Sciences, Bobo Dioulasso, Burkina Faso; ${ }^{4}$ Environmental and Agriculture Research National Institute, P.O Box 910 Bobo Dioulasso, Burkina Faso; ${ }^{5}$ Animal Health Directory, Ouagadougou, Burkina Faso

*Corresponding author: d_dahourou@yahoo.fr

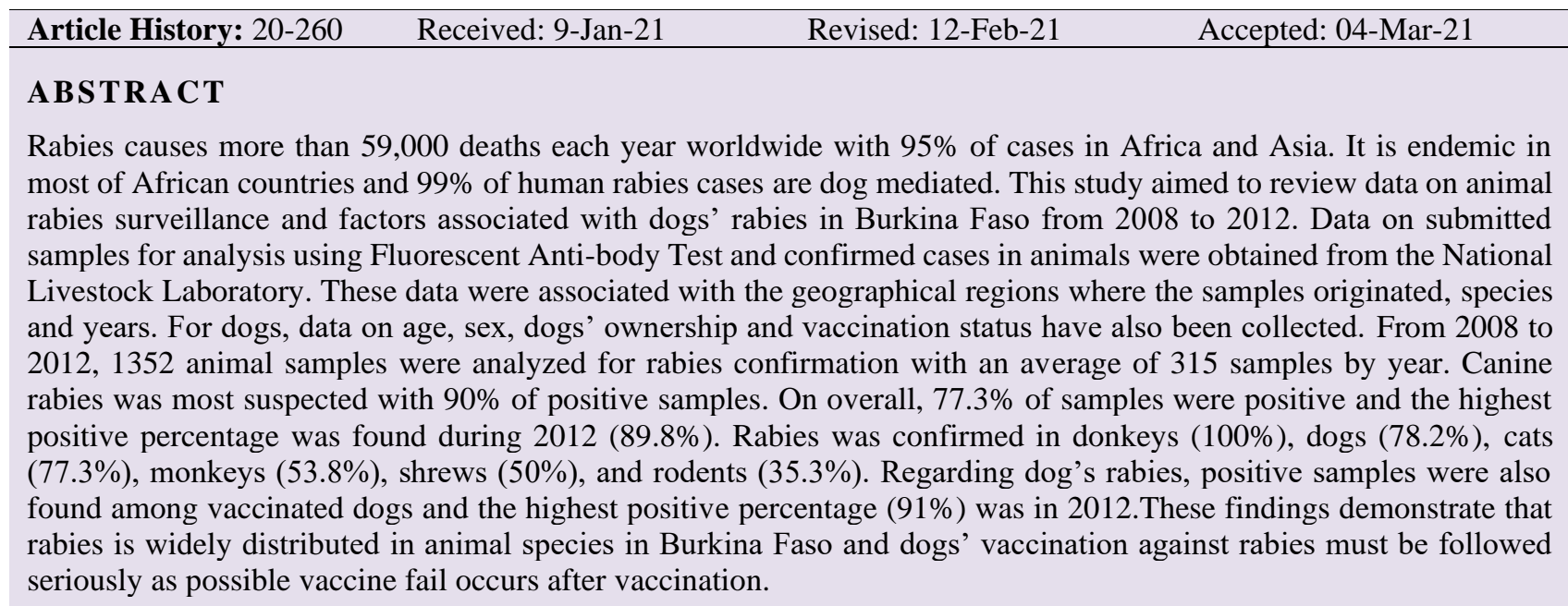

Key words: Animal, Burkina Faso, Rabies, Vaccinated dogs.

(C202I IJVS - All Rights Reserved

\section{INTRODUCTION}

Rabies is a tropical neglected zoonosis with high public health and economic importance. It causes around 59,000 human deaths worldwide each year with $36.4 \%$ located in Africa and 8.6 billion USD economic losses annually (Hampson et al. 2015). Many studies have reported that children less than 15 years old are more exposed to rabies and many human rabies cases have been reported in children (Adomako et al. 2018; Masiira et al. 2018; Yizengaw et al. 2018). All mammals including wild animals are susceptible and can transmit the rabies virus, but the primary reservoir is carnivorous mammals (Singh et al. 2017). In general, rabies transmission occurs through saliva or infected neural tissue via bite wounds or open cuts in the skin or mucous membrane (Singh et al. 2017). Dog slaughtering and the process of handling, catching, loading, transportation, holding and keeping in the cages increases the risk of transmission to the butchers (Broban et al. 2018). Non-bite exposure methods are inhalation, organ transplants and contamination of abrasions, open wounds, mucous membranes with rabies virus laden saliva or with infectious material such as brain tissue from a rabid animal (Lu et al. 2018; Pantha et al. 2020).

Globally, most (99\%) of human cases are dog mediated and result from the bite of rabid dogs (Sondo et al. 2015; Durrheim and Blumberg 2017; Penjor et al. 2019; Barrios et al. 2019). Regarding its public and economic importance, the World Health Organization (WHO), the World Organization for Animal Health (OIE), the Food and Agriculture Organization (FAO) and the Global Alliance for Rabies Control (GARC) have established "United

Cite This Article as: Minoungou G, Dahourou LD, Savadogo M, Tialla D, Comabari AHB, Kanyala E, Ouattara L, Kabore SA, Ouedraogo V, Taboure Y and Kere I, 2021. Surveillance of animal rabies in Burkina Faso: a retrospective laboratory data from 2008 to 2012. International Journal of Veterinary Science 10(3): 172-176. https://doi.org/10.47278/journal.ijvs/2021.051 
Against Rabies", as a global collaborative program that is working towards achieving the goal of "zero human rabies deaths by 2030" (Durrheim and Blumberg 2017) using the One Health approach described as the best way for rabies control (Acharya et al. 2020).

Burkina Faso, is a rabies endemic country in which human rabies cases are noted each year, mainly in children, with dogs as main vector (Sondo et al. 2015; Savadogo et al. 2020). The disease is listed among the five prioritized zoonotic diseases in the country (Burkina Faso 2017). The country is involved in the collaborative program for rabies elimination by 2030. For this elimination program in veterinary sector, two main actions are done in the country. These actions include vaccination campaigns each year and passive surveillance. Vaccinations campaigns are focused on dogs, cats and non-human primate. During the study period, 19603, 21372, 28016, 22677 and 34038 dogs have been vaccinated in 2008, 2009, 2010, 2011 and 2012 respectively. For cats, respectively $374,472,626,744$ and 806 have been vaccinated while $84,84,203,71$ and 62 nonhuman primates have been vaccinated (Ministère des ressources animales, 2015).Surveillance has been implemented for animal rabies in the country by the National Livestock Laboratory (LNE) since 2000. In this surveillance program, samples from each rabies suspect animal, from different regions in the country, are sent to the LNE for rabies diagnostic confirmation using Fluorescent Antibody Test (FAT) as previously described (Tenzin et al. 2020). Since surveillance program has been implemented data collected have never been analyzed to study distribution of rabies in animals and also factors associated with dogs' rabies, the main vector of human rabies in the country. Thus, this study aimed to review data of this surveillance program from 2008 to 2012 and study factor associated with dogs' rabies in Burkina Faso.

\section{MATERIALS AND METHODS}

\section{Study Area}

This study was focused on different regions of country from where samples are submitted to the National Livestock laboratory (LNE). The National Livestock Laboratory is based at Ouagadougou, the capital city of Burkina Faso. It is the central veterinary laboratory in the country and its activities are focused on animal diseases diagnostic, diseases surveillance and research since last years. This study was done in 12 of the 13 regions of the country. Only one region, the region of Cascades has not been added in the present study as no sample was received from this area during the study period.

\section{Methodology}

This retrospective record review covered five years from 2008 to 2012. Retrospective data were collected from record books of rabies in animals at LNE. Samples from suspected rabid animals are sent to LNE for rabies confirmation. Suspected animals were animals with rabies like symptoms, stray dogs which have bitten people or animal without any reason or rabies suspected animal that died during observation period. Each sample was sent to the laboratory with a notification sheet containing data on species, years and origin; for dogs, vaccination status and age class were included.
Samples were heads of suspected animals kept at $4{ }^{\circ} \mathrm{C}$ and sent to LNE. In the laboratory, brains from animals were aseptically collected and brain smears were prepared and subjected to Fluorescent Anti-body Test (FAT) which is a gold standard for rabies diagnosis (Duong et al. 2016). Briefly, impression smears of a cut section of the brain stem and the cerebellum were made, fixed in cold acetone and stained with a cocktail of three fluorescein-labelled monoclonal antibodies directed against the nucleocapsid (N) protein of rabies virus. Slides were observed under the fluorescent microscope and rabies positive smears gave apple color fluorescence. After laboratory analysis, results were reported in a records sheet with information from notification sheet which to build a database.

\section{Data Analysis}

Data were retrieved from records sheet and a database has been built in Excel 2007. Extracted data has been entered and analyzed in R 3.5.2 software. We perform with this software descriptive analysis. The association between canine rabies and explanatory variables (age class, sex, vaccination status, dogs' ownership, years and region) has been made using the Chi square or the Fisher Exact test at significance level $\mathrm{P}<0.05$.

\section{RESULTS}

\section{Overview of Suspected Case of Animal Rabies Received at LNE from 2008 to 2012}

For the study period, 1352 samples were received in the laboratory for rabies confirmation and 1204 (89.1\%) were canine samples. On average, more than 250 samples were received each year but 2012 noted the least suspected rabies cases (Table 1). Most of received samples were dogs sample from Center Region (Table 2).

\section{Confirmed Animal Rabies per Year, Species and Region from 2008 to 2012}

Regarding confirmed cases most of samples received were confirmed positive. During these five years, $77.4 \%$ of received samples were found to be positive (Table 3 ). Respectively $71.276 .1,71.3,79.2$ and $89.8 \%$ of samples received in 2008, 2009, 2010, 2011 and 2012 were positive. Canine rabies was the most confirmed with $90 \%$ of rabies cases (Table 3). Regarding, the region of origin, animal rabies cases were confirmed in all regions with most of cases coming from Center region (Fig. 1). Moreover, animal rabies was most prevalent in South-West region while Boucle du Mouhoun region had noted the lowest prevalence of animal rabies (Fig. 1).

\section{Situation of Canine Rabies in Burkina Faso from 2008 to 2012}

Each year, canine rabies has been confirmed in the laboratory, but the highest positive rate was found during year 2012 (Table 4). Also, rabies was confirmed in dogs in all region and all submitted samples from South-West region were positive. Among animal with known age, the positive rate was significantly higher in dogs less than 4 months (78.9\%) than those more than 4 months old (75.6\%) $(\mathrm{P}<0.01)$. Also, the positive rate was higher in stray dogs $(93.3 \%)$ than in owned dogs $(76.8 \%)$. Surprisingly, some vaccinated dogs are found to be positive to rabies and $58.9 \%$ of vaccinated dogs were tested positive to rabies (Table 4). 
Table 1: Samples received by animal species and year for rabies confirmation from 2008 to 2012

\begin{tabular}{lccccccc}
\hline Species & 2008 & 2009 & 2010 & 2011 & 2012 & Total & $\%$ \\
\hline Bat & - & - & - & - & 1 & 1 & 0.07 \\
Cat & 20 & 22 & 19 & 27 & 18 & 106 & 7.8 \\
Dog & 225 & 289 & 223 & 256 & 211 & 1204 & 89.1 \\
Donkey & - & 1 & 3 & - & - & 4 & 0.3 \\
Goat & - & - & 1 & - & 1 & 2 & 0.2 \\
Horse & - & - & 1 & - & - & 1 & 0.07 \\
Jackal & - & - & - & 1 & - & 1 & 0.07 \\
Monkey & 2 & 1 & 1 & 7 & 2 & 13 & 0.9 \\
Mouse & 4 & 2 & 2 & 2 & 2 & 12 & 0.8 \\
Rat & 1 & 3 & - & 1 & - & 5 & 0.4 \\
Sheep & 1 & - & - & - & - & 1 & 0.07 \\
Shrew & 1 & - & 1 & - & - & 2 & 0.2 \\
Total & 254 & 318 & 251 & 294 & 235 & 1352 & \\
\hline
\end{tabular}

Table 2: Samples received by animal species and region for rabies confirmation from 2008 to 2012

\begin{tabular}{|c|c|c|c|c|c|c|c|c|c|c|c|c|}
\hline \multirow[t]{2}{*}{ Species } & \multicolumn{12}{|c|}{ Region } \\
\hline & A & B & C & D & E & F & $\mathrm{G}$ & $\mathrm{H}$ & I & $\mathrm{J}$ & $\mathrm{K}$ & L Total \\
\hline Bat & - & - & - & - & - & 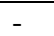 & - & - & 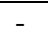 & - & 1 & - \\
\hline Cat & 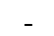 & 96 & 1 & - & 2 & 1 & 4 & 1 & 1 & 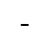 & - & 106 \\
\hline Dog & 12 & 1040 & 26 & 18 & 12 & 62 & 21 & 15 & 12 & 18 & 22 & 21204 \\
\hline Donke & 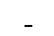 & 2 & - & - & - & - & - & - & - & - & 2 & 4 \\
\hline Goa & - & 1 & 1 & - & - & - & - & - & - & - & - & - \\
\hline Hors & - & - & - & - & - & - & - & - & - & - & 1 & - \\
\hline Jacl & - & - & - & - & 1 & - & - & - & - & - & - & - \\
\hline Mor & - & 13 & - & - & - & - & - & - & - & - & - & 13 \\
\hline Mou & - & 12 & - & - & - & - & - & - & - & - & - & 12 \\
\hline Rat & 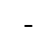 & 5 & - & - & - & - & - & - & - & - & - & 5 \\
\hline Shee & - & 1 & - & - & - & - & - & - & - & - & - & 1 \\
\hline Shre & - & 2 & - & - & - & - & - & - & - & - & - & - \\
\hline Total & 12 & 1172 & 28 & 18 & 15 & 72 & 25 & 16 & 13 & 18 & 26 & 21352 \\
\hline
\end{tabular}

A=Boucle du Mouhoun; B=Center; C=Middle-East; $\mathrm{D}=$ MiddleNorth; E=Middle-West; F=Middle-South; G=East; H=HautsBassins; I=North; J=Plateau Central; K= Sahelian; L=South-West

Table 3: Confirmed rabies cases by species and region in Burkina Faso

\begin{tabular}{lccccccc}
\hline Years & 2008 & 2009 & 2010 & 2011 & 2012 & Total & $\%$ \\
\hline Species & & & & & & & \\
Bat & - & - & - & - & 1 & 1 & 0.1 \\
Cat & 17 & 15 & 14 & 21 & 15 & 82 & 7.8 \\
Dogs & 159 & 225 & 160 & 206 & 192 & 942 & 90 \\
Donkey & - & 1 & 3 & - & - & 4 & 0.4 \\
Goat & - & - & 1 & - & 1 & 2 & 0.2 \\
Horse & - & - & - & - & - & 0 & - \\
Jackal & - & - & - & 1 & & 1 & 0.1 \\
Monkey & - & - & 1 & 4 & 2 & 7 & 0.7 \\
Mouse & 4 & - & - & - & - & 4 & 0.4 \\
Rat & - & 1 & & 1 & & 2 & 0.2 \\
Sheep & - & - & - & - & - & 0 & - \\
Shrew & 1 & - & - & - & - & 1 & 0.1 \\
Total & 181 & 242 & 179 & 233 & 211 & 1046 & 100 \\
Region & & & & & & & \\
B. du Mouhoun & 3 & 3 & 2 & - & - & 8 & 0.8 \\
Center & 157 & 216 & 140 & 196 & 192 & 901 & 86.1 \\
Middle-East & 4 & 5 & 10 & 4 & 1 & 24 & 2.3 \\
Middle-North & 2 & 6 & 2 & - & 4 & 14 & 1.3 \\
Middle-West & - & 1 & 1 & 6 & 3 & 11 & 1.1 \\
Middle-South & 2 & - & 2 & - & 2 & 6 & 0.6 \\
East & 5 & 3 & 6 & 6 & 1 & 21 & 2.0 \\
Haut-Bassins & 3 & 2 & 3 & 3 & - & 11 & 1.0 \\
North & - & - & 2 & 5 & 5 & 12 & 1.2 \\
Plateau Central & 3 & 2 & 3 & 7 & - & 15 & 1.4 \\
Sahelian & 2 & 3 & 8 & 5 & 3 & 21 & 2.0 \\
South-West & - & 1 & - & 1 & - & 2 & 0.2 \\
Total & 181 & 242 & 179 & 233 & 211 & 1046 & 100 \\
\hline & & & & & & &
\end{tabular}

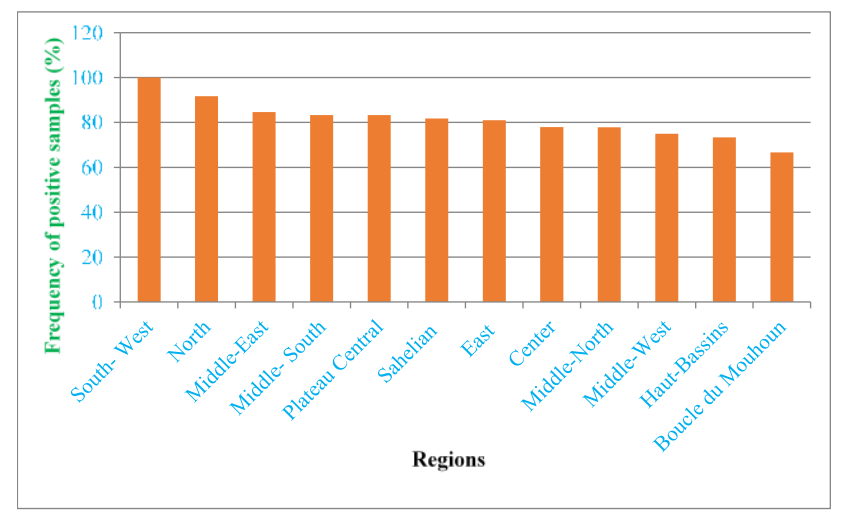

Fig. 1: Frequency of positive samples for dogs' rabies according to regions in Burkina Faso from 2008 to 2012.

\section{DISCUSSION}

During the study, we have noted that information about age, sex, origin and vaccination status of some animals were not included in the records sheet. As some animals were stray animals, this could also explain this lack of data.

Each year, more than $70 \%$ of suspected case of animal rabies has been confirmed in the laboratory. This situation suggests that animal rabies is endemic and represents a serious public health concern and veterinary problem in Burkina Faso. Different species could be vectors of rabies in the country as they were found positive, but dogs remain the most affected species and often the vectors of others species rabies. This situation has also been noted in Ethiopia where dogs are the principal vector for animal rabies (Jemberu et al. 2013; Reta et al. 2014). This could explain why dogs are the most involved in human rabies cases in Burkina Faso (Sondo et al. 2015). Rabies is widely distributed in the country but most of the cases come from the Center region which capital is Ouagadougou. This situation could be linked to an under-reporting of animal rabies in the other regions because of poor accessibility to the diagnostic laboratory, the affordability of sample shipment from other regions to LNE at Ouagadougou and the lack of knowledge of rural people on dog rabies. This situation has been reported in other African countries (Dodet and Africa Rabies Bureau (AfroREB) 2009; Nel 2013) and it could lead to an underestimation of the overall rate of animal rabies in the country.

In the present study, rabies has been confirmed for both vaccinated and unvaccinated dogs. This was also confirmed in different countries across the word (Okoh 1982; Murray et al. 2009; Salomão et al. 2017). The detection of rabies virus in vaccinated dogs could be due to vaccine failure (Nodari et al. 2017). In Burkina Faso, we face frequent power disruption, lack of cold chain during transportation of vaccines or during vaccination campaign. Thus, administration of the product does not necessarily guarantee the wanted protection. Some fluctuation of the occurrence of dog rabies was noted through the study period but the highest positive rate was found in 2012 . Also, the rate of confirmed case of rabies was significantly higher in stray dogs compared to owned dogs. This could be linked to the ease of transmission of rabies virus between stray dogs during feeding and also reproductive periods. Dogs from different age groups were positive but 
Int J Vet Sci, 2021, 10(3): 172-176.

Table 4: Situation of confirmed rabies in dogs by age, year, sex, vaccination status, ownership and region in Burkina Faso

\begin{tabular}{|c|c|c|c|c|}
\hline Variables & Samples Analyzed (No.) & Positive Samples (No.) & Percentage & P value \\
\hline \multicolumn{5}{|l|}{ Age Class } \\
\hline$\leq 4$ Months & 355 & 280 & 78.9 & \multirow[t]{3}{*}{0.0005} \\
\hline$>4$ Months & 712 & 538 & 75.6 & \\
\hline Unknown & 137 & 124 & 90.5 & \\
\hline \multicolumn{5}{|l|}{ Sex } \\
\hline Female & 337 & 262 & 77.7 & \multirow[t]{3}{*}{0.0077} \\
\hline Male & 752 & 577 & 76.7 & \\
\hline Unknown & 115 & 103 & 89.6 & \\
\hline \multicolumn{5}{|l|}{ Vaccination status } \\
\hline Vaccinated & 190 & 112 & 58.9 & \multirow[t]{3}{*}{$3.572 \mathrm{e}-12$} \\
\hline Unvaccinated & 818 & 660 & 80.7 & \\
\hline Unknown & 196 & 170 & 86.7 & \\
\hline \multicolumn{5}{|l|}{ Ownership } \\
\hline Owned & 1099 & 844 & 76.8 & \multirow[t]{2}{*}{0.000087} \\
\hline Stray & 105 & 98 & 93.3 & \\
\hline \multicolumn{5}{|l|}{ Year } \\
\hline 2008 & 225 & 159 & 70.7 & \multirow{5}{*}{0.00000073} \\
\hline 2009 & 289 & 225 & 77.9 & \\
\hline 2010 & 223 & 160 & 71.7 & \\
\hline 2011 & 256 & 206 & 80.5 & \\
\hline 2012 & 211 & 192 & 91.0 & \\
\hline \multicolumn{5}{|l|}{ Region } \\
\hline Boucle du Mouhoun & 12 & 8 & 66.7 & \multirow[t]{12}{*}{0.95} \\
\hline Center & 1040 & 810 & 77.9 & \\
\hline Middle-East & 26 & 22 & 84.6 & \\
\hline Middle-North & 18 & 14 & 77.8 & \\
\hline Middle-West & 12 & 9 & 75.0 & \\
\hline Middle- South & 6 & 5 & 83.3 & \\
\hline East & 21 & 17 & 81.0 & \\
\hline Haut-Bassins & 15 & 11 & 73.3 & \\
\hline North & 12 & 11 & 91.7 & \\
\hline Plateau Central & 18 & 15 & 83.3 & \\
\hline Sahelian & 22 & 18 & 81.8 & \\
\hline South-West & 2 & 2 & 100 & \\
\hline
\end{tabular}

The association between canine rabies and explanatory variables (age class, sex, vaccination status, dogs' ownership, years, and region) has been made using the Chi square or the Fisher Exact test at significance level $\mathrm{P}<0.05$.

among those which age was known, most of rabid dogs were less than four months. These observations are different from those reported by Reta et al. (2014) in Ethiopia. The finding of the present study could be linked to the high proportion of samples received from animals aged more than four months. Results of this study suggest that rabies is widely distributed in Burkina Faso and dogs are the most affected animals.

For now, the proportion of vaccinated animals remains low and according to Kaare et al. (2009), the percentage of vaccinated dog to eliminate rabies in dogs' populations and prevent future outbreaks is predicted to be around $70 \%$. In the case of Burkina Faso, the proportion of vaccinated dogs is difficult to estimate as no data on dog population are available. To better control dog mediated rabies, it is very important to monitor dog mass vaccination campaigns with a follow up of vaccines and vaccination practices to reduce vaccination failure. It is also necessary to estimate dog population in the country and their ecology and ownership.

In conclusion, to be more effective future vaccination campaigns against dog rabies need to be accompanied by a scientific evaluation in the light of data generated from an active rabies surveillance system, on-going studies on knowledge about the awareness of the human populations and further field studies focused on vaccine efficacy, monitoring of antibodies level in vaccinated animals, dog demography and ecology as well as the optimal timing and periodicity of vaccination campaigns.

\section{Conclusion}

These data confirmed that animal rabies is widely distributed in the country with many animal host species but dogs remain the main vector of human rabies. Rabies was most important in stray dogs and we have also found that vaccinated dogs were infected. This suggests that dog vaccination must be improved in the country with a control with antibodies response in vaccinated animals.

\section{Acknowledgments}

We thank all field technicians for specimens' collection and submission. We are also grateful to animal owners for allowing us to work on their animal samples.

\section{Author's Contribution}

The study has been designed by MG, DLD and SM. Laboratory analyses have been made by KE, OL, KAS, $\mathrm{OV}$, TY and KI under the supervision of MG and AT. The extraction of data from the database has been done by TD, CAHB. Statistical analyses have been made by DLD and SM and validated by AT. All authors have read and approve the manuscript. 


\section{REFERENCES}

Acharya KP, Acharya N, Phuyal S, Upadhyaya M and Lasee S, 2020. One-health approach: A best possible way to control rabies. One Health 10: 100161. https://doi.org/10.1016/ j.onehlt.2020.100161

Adomako B-Y, Baiden F, Sackey S, Ameme DK, Wurapa F, Nyarko KM, Kenu E and Afari E, 2018. Dog bites and rabies in the Eastern Region of Ghana in 2013-2015: A call for a one-health approach. Journal of Tropical Medicine 2018: 6139013. https://doi.org/10.1155/2018/6139013

Barrios CL, Vidal M, Parra A, Valladares C, González C and Pavletic C, 2019. Epidemiological characterization of bites: A retrospective study of dog bites to humans in Chile during 2009. Journal of Veterinary Behavior 33: 31-37. https://doi.org/10.1016/j.jveb.2019.04.006

Broban A, Tejiokem MC, Tiembré I, Druelles S and Azou M, 2018. Bolstering human rabies surveillance in Africa is crucial to eliminating canine-mediated rabies. PLOS Neglected Tropical Diseases 12: e0006367. https://doi.org/ 10.1371/journal.pntd.0006367.

Burkina Faso, 2017. 'One health zoonotic disease prioritization for multisectoral engagement in Burkina Faso.

Dodet B and Africa Rabies Bureau (AfroREB), 2009. The fight against rabies in Africa: From recognition to action. Vaccine 27: $\quad$ 5027-5032. https://doi.org/10.1016/j.vaccine. 2009.06.030

Duong V, Tarantola A, Ong S, Mey C, Choeung R, Ly S, Bourhy $\mathrm{H}$, Dussart P and Buchy P, 2016. Laboratory diagnostics in dog-mediated rabies: an overview of performance and a proposed strategy for various settings. International journal of infectious diseases: IJID: official publication of the International Society for Infectious Diseases 46: 107-114. https://doi.org/10.1016/j.ijid.2016.03.016

Durrheim DN and Blumberg L, 2017. Rabies - what is necessary to achieve 'zero by 30'? Transactions of The Royal Society of Tropical Medicine and Hygiene 111: 285-286. https://doi.org/10.1093/trstmh/trx055

Hampson K, Coudeville L, Lembo T, Sambo M, Kieffer A, Attlan M, Barrat J, Blanton JD, Briggs DJ, Cleaveland S, Costa P, Freuling CM, Hiby E, Knopf L, Leanes F, Meslin F-X, Metlin A, Miranda ME, Müller T, Nel LH, Recuenco S, Rupprecht CE, Schumacher C, Taylor L, Vigilato MAN, Zinsstag J and Dushoff J, 2015. Estimating the global burden of endemic canine rabies. PLoS Neglected Tropical Diseases 9: e0003786. https://doi.org/10.1371/journal.pntd.0003786

Jemberu WT, Molla W, Almaw G and Alemu S, 2013. Incidence of rabies in humans and domestic animals and people's awareness in North Gondar Zone, Ethiopia (CE Rupprecht, Ed.). PLOS Neglected Tropical Diseases 7: e2216. https://doi.org/10.1371/journal.pntd.0002216

Kaare M, Lembo T, Hampson K, Ernest E, Estes A, Mentzel C and Cleaveland S, 2009. Rabies control in rural Africa: evaluating strategies for effective domestic dog vaccination. Vaccine 27: 152-160. https://doi.org/10.1016/j.vaccine. 2008.09.054

Lu XX, Zhu WY and Wu GZ, 2018. Rabies virus transmission via solid organs or tissue allotransplantation. Infectious Diseases of Poverty 7: 82. https://doi.org/10.1186/s40249-018-04677.

Masiira B, Makumbi I, Matovu JKB, Ario AR, Nabukenya I, Kihembo C, Kaharuza F, Musenero M and Mbonye A, 2018. Long term trends and spatial distribution of animal bite injuries and deaths due to human rabies infection in Uganda, 2001-2015. Plos One 13: e0198568. https://doi.org/10.1371/ journal.pone. 0198568

Ministère des ressources animales, 2015. 'Annuaire des statistiques de l'élevage 2014.' (Ouagadougou, Burkina Faso).
Murray KO, Holmes KC and Hanlon CA, 2009. Rabies in vaccinated dogs and cats in the United States, 1997-2001. Journal of the American Veterinary Medical Association 235: 691-695. https://doi.org/10.2460/javma.235.6.691.

$\mathrm{Nel}$ LH, 2013. Discrepancies in data reporting for Rabies, Africa. Emerging Infectious Diseases 19: 529-533. https://doi.org/ 10.3201/eid1904.120185.

Nodari ER, Alonso S, Mancin M, Nardi MD, Hudson-Cooke S, Veggiato C, Cattoli G and Benedictis PD, 2017. Rabies vaccination: Higher failure rates in imported dogs than in those vaccinated in Italy. Zoonoses and Public Health 64: 146-155. https://doi.org/10.1111/zph.12268.

Okoh A, 1982. Canine rabies in Nigeria, 1970 - 1980 reported cases in vaccinated dogs. International Journal of Zoonoses 9: 118-125.

Pantha S, Subedi D, Poudel U, Subedi S, Kaphle K and Dhakal S, 2020. Review of rabies in Nepal. One Health 10: 100155. https://doi.org/10.1016/j.onehlt.2020.100155

Penjor K, Tenzin T and Jamtsho RK, 2019. Determinants of health seeking behavior of animal bite victims in rabies endemic South Bhutan: a community-based contact-tracing survey. BMC Public Health 19: 237. https://doi.org/10.1186/ s12889-019-6559-x.

Reta T, Teshale S, Deresa A, Ali A, Mengistu F, Sifer D and Freuling CM, 2014. Rabies in animals and humans in and around Addis Ababa, the capital city of Ethiopia: A retrospective and questionnaire based study. Journal of Veterinary Medicine and Animal Health 6: 178-186. https://doi.org/10.5897/JVMAH2013.0256.

Salomão C, Nacima A, Cuamba L, Gujral L, Amiel O, Baltazar C, Cliff $\mathrm{J}$ and Gudo ES, 2017. Epidemiology, clinical features and risk factors for human rabies and animal bites during an outbreak of rabies in Maputo and Matola cities, Mozambique, 2014: Implications for public health interventions for rabies control. PLOS Neglected Tropical Diseases 11: e0005787. https://doi:10.1371/journal.pntd. 0005787.

Savadogo M, Koné P, Dahourou LD, Manishimwe R, Sow A, Nébié L, Antoine-Moussiaux N, Doulkom B and BadaAlambedji R, 2020. Epidémiologie de la rage et connaissance, attitudes et pratiques des communautés au Burkina Faso. Revue d'élevage et de Médecine Vétérinaire des Pays Tropicaux 73: 133-140. https://doi.org/ 10.19182/remvt.31863.

Singh R, Singh KP, Cherian S, Saminathan M, Kapoor S, Manjunatha Reddy GB, Panda S and Dhama K, 2017. Rabies - epidemiology, pathogenesis, public health concerns and advances in diagnosis and control: a comprehensive review. Veterinary Quarterly 37: 212-251. https://doi.org/10.1080/ 01652176.2017.1343516.

Sondo KA, Yonaba/Okengo C, Diop SA, Kabore BE, Diallo I, Kyelem N, Basshono J, Thombiano R and Kam L, 2015. Rabies in children: report of 24 cases at the Yalgado Ouedraogo University Hospital Center of Ouagadougou in Burkina Faso. Journal of Tropical Diseases \& Public Health 3: 1-5. https://doi.org/10.4172/2329-891X.1000168.

Tenzin T, Lhamo K, Rai PB, Tshering D, Jamtsho P, Namgyal J, Wangdi T, Letho S, Rai T, Jamtsho S, Dorji C, Rinchen S, Lungten L, Wangmo K, Lungten L, Wangchuk P, Gempo T, Jigme K, Phuntshok K, Tenzinla T, Gurung RB and Dukpa K, 2020. Evaluation of a rapid immunochromatographic test kit to the gold standard fluorescent antibody test for diagnosis of rabies in animals in Bhutan. BMC Veterinary Research 16: 183. https://doi.org/10.1186/s12917-02002405-4.

Yizengaw E, Getahun T, Mulu W, Ashagrie M, Abdela I and Geta M, 2018. Incidence of human rabies virus exposure in northwestern Amhara, Ethiopia. BMC Infectious Diseases 18: 597. https://doi.org/10.1186/s12879-018-3500-3. 